\title{
TRES TEORÍAS DE LA FICCIÓN
}

\author{
THREE THEORIES OF FICTION
}

TRÊS TEORIAS DA FICÇÃO

\author{
Nicolás Lavagnino \\ (Universidad de Buenos Aires) \\ nicolaslavagnino@gmail.com
}

Recibido: 22/12/2020

Aprobado: 14/01/2021

\begin{abstract}
RESUMEN
Este trabajo se propone analizar y comparar tres teorías de la ficción, las de Bentham, Vaihinger y Frye, que consideran a la misma como un constructo hipotético. El objetivo general es mostrar que en las concepciones benthamita y vaihingeriana de la ficción obran una serie de condicionamientos y restricciones que culminan cercenándole sus extensiones filosóficas más relevantes. En este sentido, se afirma, las dos primeras teorías no terminan por descerrajar los grilletes que limitan al procedimiento ficcional, lo cual tan solo ocurre cuando es una tercera aproximación teórica, la de Frye, la que es tenida en cuenta.
\end{abstract}

Palabras clave: ficción. constructo hipotético. teoría del mýhtos. desplazamiento. diatessaron.

\section{ABSTRACT}

This article analyzes and compares three fiction theory approaches, Bentham, Vaihinger, and Frye, which consider fiction theory a hypothetical construct. The general objective is to show that in the Benthamite and Vaihingerian concepts of fiction, there are a series of constraints and restrictions that restrain their most relevant philosophical extensions. In this sense, it is stated, the first two theories do not succeed in unlocking the shackles that limit the fictional procedure, which only happens when a third theoretical approach is considered, that of Frye.

Keywords: fiction. hypothetical construct. mythos theory. displacement. diatessaron.

\section{RESUMO}

Este trabalho tem como objetivo analisar e comparar três abordagens da teoria da ficção a partir de Bentham, Vaihinger e Frye, autores que a consideram um construto hipotético. $\mathrm{O}$ objetivo geral é mostrar que nas considerações benthamita e vaihingeriana do conceito de ficção há uma série de condicionamentos e restrições que culminam no recorte de suas extensões filosóficas mais relevantes. Nesse sentido, afirma-se que as duas primeiras teorias não terminam em liberar dos grilhões que limitam o procedimento ficcional, o que só acontece quando se considera uma terceira abordagem teórica, a de Frye. 
Palavras-chave: ficção. construto hipotético. teoria do mýthos. deslocamento. diatessaron.

\section{Introducción}

En un texto originalmente titulado "An old question raised again" (traducido al español como "Hecho y figuración en el discurso histórico"; White, 2003), Hayden White señala lo siguiente: “¿La presencia en un discurso histórico de elementos «literarios» vicia su pretensión de contar la verdad y sus procedimientos de verificación y falsación? Sólo si uno iguala el escrito literario con la mentira o la falsificación y niega a la literatura cualquier interés en representar la realidad de un modo realista" (White, 2003: 54). Podemos recordar aquí que la poética de la historia whiteana se postulaba como un procedimiento para analizar el discurso de la historia como ficcionalización, por medio del escrutinio de los operadores tropológicos presentes en el lenguaje ordinario (White, 1992; Lavagnino, 2013). Es en ese contexto que White afirma que está entendiendo al concepto de ficción "para ser comprendido en su sentido benthamita y vaihingeriano moderno, es decir, como un constructo hipotético" (White, 2003: 55), una consideración como si de una realidad determinada.

En este artículo pretendo indagar en esta curiosa afirmación whiteana, asumiendo un punto de vista cercano al de White pero yendo más allá de él, y en particular teniendo en cuenta no sólo las diferencias y contradicciones entre las posiciones de Jeremy Bentham y Hans Vaihinger, sino también la presencia de una tercera teoría de la ficción, presente en la obra de Northrop Frye, que podría servir mejor a los fines de la construcción hipotética de un modelo relativo a una realidad que debe ser imaginada o concebida antes de ser representada o presentada en forma de discurso en prosa.

El objetivo general es mostrar que en la tradición de pensamiento asociada al moderno concepto de ficción obran una serie de condicionamientos y restricciones que culminan amputándole sus extensiones filosóficas más relevantes. En este sentido, se afirma, la tradición benthamita y vaihingeriana no termina por descerrajar los grilletes que limitan al procedimiento ficcional, lo cual tan solo ocurre cuando es una tercera aproximación teórica, la de Frye, la que es tenida en cuenta.

\section{Bentham y el fétido y ponzoñoso aliento de la ficción}

Los orígenes del término ficción se remontan a la voz latina fictio, cuya definición canónica implica la acción o efecto de pretender que algo es cierto. Como ítems léxicos encontramos fingere (modelar, aparentar, simular), conservado en la raíz fic-, y la parte sufija -ción, que es de acción o efecto. El componente modélico se preserva en términos asociados como efigie, que se conecta con la vieja teoría de raíz platónica sobre la mimesis como imitatio (reproducción o copia, en el sentido de degradación ontológica), aunque sabemos que eso no es todo lo que puede decirse sobre la mímesis, ni en sentido imitativo ni en lo que respecta a la ontología (Blumenberg, 1999).

En este punto ya tenemos varias ideas conectadas: la idea del modelo, la de la presentación objetual de algo (que se encuentra en términos conexos como configuración o figuración), la de la reproducción y la de la degradación ontológica. Lo interesante es que sólo en las últimas dos (y en especial en la última) se implica un matiz intencional de duplicación y engaño, como fingimiento o simulación (en el inglés pretense) o un "hacerse pasar por" que implica falsedad. En cambio, en las primeras se encuentran presentes las nociones de ideación y disposición (por ejemplo en los términos contrive y concoct), lo que involucra un rango semántico que va desde los posiblemente maliciosos pergeñar y tramar, hasta los más neutros y proyectivos elaborar, construir, montar y efectuar.

En tanto efectuación y disposición de la cosa, la voz fictio se aúna con factum, ya que ambas remiten a algo hecho o lo que puede ser concebido, diseñado y dispuesto (White, 2003: 55). En este contexto lo hecho también se analoga a lo realizado por medio de un acto de voluntad, y no extrañamente a lo ejecutado lo cual es recogido en el latín medieval factum, como aquello que se dispone en forma de evento, ocurrencia o estado de cosas como resultado de la ejecución de la voluntad de una persona. 
En esta maraña terminológica encontramos, entonces, la permanente ligazón de tres elementos: la existencia de una disposición que se "presenta" (por ejemplo, en forma objetual o verbal), la consideración de una capacidad de intervención práctica, de hechura, que se deriva de una ideación que responde a una intención en particular y, finalmente, la atribución a esa intención de un carácter. Alguien hace algo, y lo presenta (en el sentido recogido por la voz alemana Darstellung; cfr. Helfer, 1996; White, 2010: 43n) con un determinado propósito. El problema, en este conjunto de derivas etimológicas, no es tanto la realidad de la cosa dispuesta, sino su carácter atribuido, en particular la posibilidad de la duplicidad, la simulación o, en el límite, el engaño.

Esto podría expresar la recurrencia a la desconfianza en torno a la capacidad que tenemos de darnos nuestros propios objetos, de crear entidades de por sí, algo que en una cosmovisión dada (por ejemplo, la cristiana) adquiere usualmente visos de sospecha: somos criaturas imaginativas y capaces de pergeñar dispositivos, pero jay!, nuestra condición moral degradada contamina el complejo fictio-factum con las notas distintivas de la duplicidad ontológica y la malicia (Frye, 1963: 29). Hasta aquí la idea genérica y sumamente discutible de la visión clásica, cimentada en la Antigüedad, del concepto de ficción.

Ahora bien, para la teoría de la ficción es un lugar común recurrir a la obra de Bentham al momento de analizar la introducción de este complejo temático en el pensamiento moderno. La teoría de la ficción de Bentham no es sencilla pero, en esencia (siguiendo su Teoría de las ficciones, su Tratado de legislación civil y penal, su Fragmento sobre el gobierno o sus críticas a Blackstone y al Common Law) se reduce a lo siguiente: entiende por ficción, en el ámbito del derecho, y con especial atención al problema de la ficción jurídica, "un hecho notoriamente falso sobre el que se razona como si fuera verdadero" (Bentham, 1981: 83). Ciertamente, para cualquier interesado en rescatar una teoría benthamita de la ficción, como White, debería considerarse de manera liminar que la concepción de Bentham sobre ellas no era muy positiva. Lo que interesaba a nuestro autor era la situación de la legislación y la práctica jurídica inglesa de su tiempo, en la cual "el fétido aliento de la ficción emponzoña el significado de cuanto empaña” (Bentham, 1973: 25).

Pero ¿por qué "fétido aliento"? Pues porque en una ontología empirista clásica que seguía a Locke y a Hume, en la cual todas nuestras ideas proceden de nuestros sentidos, podía distinguirse claramente entre las entidades reales, representadas por los modos simples de Locke, y las entidades abstractas a las que refieren los modos mixtos (Bentham, 1973: 127n). "Todas nuestras ideas proceden de nuestros sentidos y el único camino de presentar cualquiera de nuestras ideas clara y determinadamente es ascender hasta los objetos sensibles en los que se origina" (Bentham, 1970: 294). En el universo ontológico de Bentham solo hay entidades reales, lo que incluye sustancias corporales y cosas materiales, impresiones sensibles o ideas (Hart, 1982: 129). Lo relevante, en este esquema binario orientado al análisis ontológico, es que los modos mixtos son ficciones y las ficciones no existen (Bentham, 1973: 127n). Pero ese es apenas el comienzo del tratamiento benthamita del problema de la ficción.

En principio, como ya dijimos, para Bentham la ficción no es otra cosa más que "un hecho notoriamente falso sobre el cual se razona como si fuera verdadero" (Bentham, 1981: 83). De allí que considere que "una entidad ficticia es una entidad a la cual por la forma gramatical del discurso empleado al hablar de ella se le adscribe existencia, sin embargo ello no significa que la existencia se le adscriba real y verdaderamente" (Bentham, 1932: 12). Cabe decir que todas estas distinciones y sutilezas tenían un propósito. En el contexto de su pelea contra las concepciones iusnaturalistas, Bentham estaba interesado en eliminar como ficciones parásitas de la realidad a entidades tales como los derechos naturales, el contrato social y demás entidades fabulosas que debían ser erradicadas de la fundamentación de las prácticas jurídicas (Bentham, 1932: 17). Pero otras entidades, tales como las nociones de obligación, derecho, poder y competencia, que constituyen el esqueleto de las normas, también presentaban el problema de ser abstractas $\mathrm{y}$, sin embargo, eran necesarias.

Las primeras, entonces, debían ser eliminadas sin más. Las segundas, en cambio, debían ser reconducidas dentro del recinto ficcional a través de lo que Bentham llama el método de la paráfrasis. Y esta diferencia de actitud obedece al hecho de que mientras las primeras remiten a entidades no 
existentes, o fabulosas, las segundas dan cuenta de entidades ficticias. En su teoría de las ficciones, entonces, se reconocen no-existencias diversas. Las entidades fabulosas son dañinas y perniciosas para la práctica jurídica. Las entidades ficticias son aquellas que no-existiendo adquieren la forma gramatical de las cosas que sí existen. Pero son necesarias y recuperables por medio del método de la paráfrasis.

La paráfrasis, a su vez, es un método de traducción que implica tomar una proposición cuyo sujeto gramatical es una entidad ficticia, y hacerla equivaler o corresponder con una proposición cuyo sujeto sea una entidad real (Bentham, 1983: 75). Este "método" sería una suerte de análisis lógico de las oraciones en que aparecen entidades abstractas, con la finalidad de esclarecer aquello que nombran o designan. El problema para la ciencia jurídica es que términos fundantes de la disciplina, como obligación o derecho, no designan ni nombran nada, aunque podemos comprender perfectamente lo que significan. Es decir, el término obligación no nombra ni refiere a nada, y sin embargo comprendemos lo que significa una obligación porque podemos traducir las oraciones en las que el término aparece a expresiones significativas.

Mediante este método, entonces, encontramos supuestamente una forma de enmarcar el fenómeno ficcional: se trata de un procedimiento por medio del cual utilizamos modos mixtos para hablar de entidades que no existen. Esas entidades, a su vez, no son más que la conjunción de dos entidades reales. Por ejemplo:

un acto es una entidad real; una ley es otra. Un deber o una obligación es una entidad ficticia concebida como resultante de la unión de las dos anteriores. Una ley ordenando o prohibiendo un acto crea de ese modo un deber o una obligación (Bentham, 1970: 93-94).

Pero la ley y el acto existen, y la obligación no, sin embargo, ésta adquiere para nosotros un carácter de existente ficcional, es decir, no existe en absoluto, pero su consideración es imprescindible para el requisito jurídico de perfección de la norma.

Es este método el que según Bentham permitía discriminar entre su posición y la del iusnaturalismo que requería afirmar la existencia de leyes naturales que fundan obligaciones y derechos. En este punto su moderación ontológica se saciaba al afirmar que las normas del derecho natural son absolutamente vacías de significado ya que no pueden satisfacer este método de la paráfrasis cabalmente. Las entidades fabulosas del derecho natural son "sonidos sin significado, disparates sobre zancos, círculos cuadrados y cuerpos incorpóreos" que se da la mente humana cuando es capaz de concebir cosas que no existen (Harrison, 1983: 104).

Sin embargo, detrás de toda esta prudencia anida una posibilidad para las ficciones, y en esto consiste el paso adelante dado por Bentham respecto de la posición clásica sobre la ficción, que remitía sin más a la noción de fingimiento, engaño y duplicación ontológica: se distinguen en ellas las falsedades intencionadas que conducen a las ficciones legales fabulosas, por un lado, y las entidades ficticias necesarias para la elaboración de la ciencia jurídica, por el otro.

La paradoja de esta teoría, entonces, es que afirma poder distinguir entre las ficciones fétidas y ponzoñosas, y aquellas que son necesarias pese a remitir a entidades inexistentes. La resolución de esta aporía en torno a lo inexistente necesario se confía a un método, el de la paráfrasis, que logrará (en teoría) traducir y hacer corresponder aquello que la mente requiere para operar en términos de actos y estados de cosas concretos.

Este recorrido por la teoría de Bentham tiene por función establecer la posición mínima en torno a la ficción en la época moderna, que es algo así como el sustrato reflexivo sobre el que se montan las demás teorías sobre este término. En esta aproximación, la ficción se recorta claramente de lo real, por un lado, y de lo fabuloso, por el otro, mediante un método seguro, el de la paráfrasis, que permite eliminar el riesgo del acrecimiento ontológico por vía de nominación (la creación de una realidad por medios puramente lingüísticos). Si hay una ponzoña fétida de la que hay que guardarse es de esa capacidad creativa y de duplicación que tienen nuestros dispositivos gramaticales en el enredo del lenguaje. 
A estas alturas debería ser notorio que el presupuesto que informa a esta primera aproximación al concepto de ficción es que toma como su punto de partida una diferenciación entre el vehículo ficcional y lo que tenemos por real o efectivamente el caso. En la definición de Bentham las ficciones remiten a hechos notoriamente falsos. En ningún momento se presupone una dificultad al respecto: por caso, los actos existen, las obligaciones no, aunque son necesarias; los derechos naturales tampoco, y son nefastos. La relación oposicional entre ficción y realidad aquí se da por supuesta, porque quienes emplean el dispositivo ficcional se supone que ya de antemano saben qué es el caso y qué no lo es. En su fetidez ponzoñosa no es raro que la ficción se anudara al fingere y a la duplicidad ontológica, antes que a su carácter disposicional, modélico o de diseño e ideación (concoct, contrive).

De aquí en más, en la estela de la teoría benthamita de las ficciones, el grueso de la literatura sobre la ficción ata su suerte a este carácter oposicional de la ficción con lo real, en la que todo el problema reside en amañar un método que permita comprender y domeñar el funcionamiento de un vehículo de tan complejas y enrevesadas propiedades.

Por dar tan solo un ejemplo, el clásico contemporáneo de Gregory Currie The nature of fiction (Currie, 1990) comienza estableciendo de manera decidida una oposición entre la literatura ficcional y la no ficcional que culmina por reconocer que "la ficcionalidad no reside en el texto mismo, sino en sus propiedades relacionales" (Currie, 1990: 3), esto es, semánticas. Es habitual que desde una perspectiva filosófica se postule que la clave de la ficcionalidad se basa en que sus enunciados no se comprometen con la verdad y que sus términos no necesariamente refieren. Ahora bien, esa claridad conceptual podría perderse, según Currie, si problematizáramos lo suficiente la cuestión de la verdad o la referencia, de manera que ningún tipo de texto satisficiera de antemano algún criterio al respecto, con lo cual, según él, la diferencia entre ficción y no ficción se perdería por completo.

Claro que Currie no quiere esa problematización. Otra posibilidad dentro de este dilema son las ocasionales verdades contenidas en el recurso ficcional, como cuando Conan Doyle le hace decir a Sherlock Holmes que llovió en Londres el primero de enero de 1895, lo que al parecer fue el caso. Si el valor de verdad no ofrece un test decisivo para la ficción ¿cómo podemos distinguir la ficción de lo que no lo es? Una alternativa puede proponerse de la mano de la teoría de los actos de habla y la idea de la ficción como simulación (pretense theory; Currie, 1990: 13; Searle, 1979). A este respecto la discusión relevante en el horizonte contemporáneo se da entre las posiciones de Searle y Currie: ambos acuerdan en la necesidad de establecer un criterio claro de distinción; en lo que difieren es en los costos teóricos que están dispuestos a pagar para ello.

Para Searle la diferencia relevante se da respecto del tipo de acto ilocucionario que performa quien ficcionaliza, el cual se encuentra funcionalmente vinculado al significado del enunciado (Searle, 1979: 64) y al contexto en que se ejecuta. "Los actos ilocucionarios de simulación que constituyen una obra de ficción se vuelven posibles por la existencia de un conjunto de convenciones que suspenden la operación normal de las reglas que relacionan a los actos ilocucionarios con el mundo" (Searle, 1979: 67). Al ficcionalizar el autor simula un acto de enunciación que en realidad no se encuentra vinculado a un compromiso veritativo ni a obligación alguna de proveer evidencias que respalden sus enunciados.

Pero para Currie esto no puede ser así (Currie, 1990: 18), ya que supone una definición puramente negativa del concepto de ficción. El recorrido de Currie se prolonga por la teoría de los actos de habla, la interacción comunicativa, la teoría del make-believe (Currie, 1990: 19), y la teoría de Grice en torno a los intercambios conversacionales. Siguiendo a Kendall Walton, Currie considera a la ficción una actividad compartida, morigerando con ello su aspecto unilateral remitido a las intenciones de los hablantes. En tanto transacción involucra a una audiencia, ciertos rasgos formales del medio verbal y a su autor. Pero el costo de esta maniobra, a su vez, reside en que considera a la ficcionalidad como un tipo de actividad paralela, que se disocia por completo de los usos asertóricos y veritativos del lenguaje (Herman, Jahn y Ryan, 2005: 249).

Si como acto comunicativo la ficción se recuesta en un hacer-creer, según Currie, un enunciado ficcional (y todavía aquí seguimos trabajando en una ontología ficcional centrada en enunciados; como veremos 
más adelante la cuestión del discurso ficcional ni siquiera se plantea) mínimamente "debe satisfacer dos condiciones: debe ser el producto de una intención ficcional y debe ser, como mucho, accidentalmente verdadera" (Currie, 1990: 49). El recurso a la intencionalidad no es menor aquí, ya que es esa intención ficcional la que nos aparta del terreno de la teoría de la simulación. Para Currie "la ficción es el producto de un cierto tipo de acto comunicativo, un acto de fiction-making por parte del autor. Es un acto con una estructura a lo Grice, formalmente similar a la estructura de la aserción, pero que difiere de ella en la intención de su resultado" (Currie, 1990: 51).

Como vemos, en toda esta recuperación del problema de la ficción, con sus notas asociadas a la simulación, el hacer-creer y la intencionalidad, resurge, pese a todo su refinamiento analítico, la misma criba de problemas y definiciones asociadas a una tradición de pensamiento benthamita que restringe el concepto de ficción dentro de los estrechos límites establecidos canónicamente relativos a un régimen de oposición entre lo real y lo ficcional. De esta manera las conclusiones a las que arriba Currie son, según él mismo reconoce, "conservadoras" (Currie, 1990: 217) y culminan reforzando las distinciones y dicotomías que han lastrado la tradición de pensamiento sobre este concepto.

Incorporada a una dimensión dialógica y conversacional, donde rige el hacer-creer regido por intenciones autorales, la ficcionalidad culmina siendo no más que un recinto particularizado en el que se reafirman los métodos de escrutinio de términos y enunciados que se vuelven inteligibles en cuanto analizamos la forma en que se desenvuelve la comunicación y las creencias de los que participan en ella.

Vale decir, al final de un escrupuloso recorrido filosófico, en aproximaciones como las de Currie, sigue operando el presupuesto de la duplicación y el del carácter intencionado, en un planteamiento que estipula la contraposición manifiesta entre las intenciones normales de los hablantes hacia lo que es el caso, y aquellas intenciones manifiestamente otras en la que quienes intervienen en la discusión tienen presente que no es el caso.

De este modo, de Bentham a Currie, a pesar de las muchas diferencias en el detalle de sus respectivos planteamientos, no tenemos un grado de avance sustantivo en la cuestión crucial que estructura este artículo: la superación del régimen oposicional que se tiende entre el concepto de realidad y el concepto de ficcionalidad. Todo cuanto resta establecer es el costo teórico derivado de la distinción que se realiza, la cual obra como punto de partida de todo el análisis.

\section{Vaihinger y el andamio incremental}

Si la ciencia jurídica fue un primer ámbito para la teoría de las ficciones, encontramos un segundo ámbito donde prosperó, la filosofía de la ciencia, aunque configurándose de un modo peculiar, en particular en la obra de Hans Vaihinger y su Filosofía del como si (1911; Vaihinger, 1924), y dando lugar a lo que mucho después dio en llamarse ficcionalismo (Fine, 1993: 2). Pero para entender esta segunda aproximación debemos comprender su contexto de emergencia.

Ciertamente el recorrido de Vaihinger en su trayectoria filosófica no puede ser más variopinto. Si debemos a Vaihinger la acuñación del término positivismo lógico, eso es menos notable que el hecho de que realizó el intento más exhaustivo en pos de montar una aproximación sistemática a las "ficciones teóricas, prácticas y religiosas de la humanidad", tal el subtítulo de su obra cumbre (Fine, 1993: 3).

Cercano a lo que luego fue el Círculo de Viena (aunque la mayor parte de los integrantes de ese círculo no desearan en lo más mínimo su proximidad), la obra de Vaihinger es un prolongado esfuerzo por conectar sus diversos intereses, principalmente el estudio crítico de Kant y la configuración de una teoría de las ideas y de la lógica del conocimiento científico. En sus comienzos, ciertamente, Vaihinger estaba intentando asociarse a una concepción positiva, empirista del conocimiento, distanciándose de las orientaciones racionalistas y platónicas. Su posición anti-metafísica, no le valió las simpatías de los positivistas lógicos como Moritz Schlick, que lo criticaron agriamente al considerarlo un idealista (Schlick, 1932: 107). Y sin embargo el punto de desacuerdo, según Arthur Fine, quizás se deba 
mayormente a la confusión acerca del alcance de la teoría de las ideas de Vaihinger, la cual era menos idealista que positiva en su intento de adoptar una actitud empirista hacia ellas (Fine, 1993: 4).

Esta posición incómoda se ve agravada por el hecho de que su teoría de las ficciones se plasma en un texto y una perspectiva que sufrió numerosas mutaciones desde su primera aparición como disertación en 1877 hasta su publicación como libro en 1911.

La aproximación a Kant de Vaihinger era tan peculiar como su relación con la obra de Nietzsche. En esta triangulación se finca la perspectiva particular de nuestro autor. La clave reside en que para Vaihinger los principios científicos en vez de ser constitutivos de la posibilidad del conocimiento objetivo, constituyen ficciones que funcionan como ideas regulativas (Fine, 1993: 4). Este es el punto en el que se anclan y adquieren consistencia las diversas preocupaciones filosóficas de Vaihinger: su interés se centra en el rol de los elementos ficcionales en el pensamiento y la acción humanas. Y es por ello que se propuso mostrar mediante un estudio detallado el uso inescapable de las ficciones en la teoría política, el derecho, la matemática, la filosofía y la religión, considerando como antecedentes al mismo Bentham, a Kant y a Nietzsche entre otros.

Lo que caracteriza a las ficciones, para Vaihinger, son tres cosas: 1) están en contradicción con la realidad; 2) son auto-contradictorias y 3 ) ambos aspectos son conocidos cuando se las introduce (Fine, 1993: 5). Las semi-ficciones no presentan la segunda característica. A partir de esta definición pueden reconocerse ficciones virtuosas, viciosas, científicas y no científicas. Para Vaihinger, por ejemplo, los átomos (como centros sin extensión, en la definición de Ampere) y la cosa en sí kantiana son ficciones virtuosas. Las ficciones, luego, son clasificadas en una suerte de anatomía que las distribuye en 10 categorías (siendo las más importantes las abstractivas, esquemáticas, analógicas, legales, personificatorias, heurísticas, prácticas y matemáticas).

Lo que diferencia parcialmente a Vaihinger respecto de la aproximación benthamita que se arrastra hasta Currie, tal como vimos antes, es el rol de las ficciones en el acrecimiento del conocimiento. Las ficciones cuando se introducen entran en contradicción con lo que es tenido por real (Vaihinger 1924: 86). Ciertamente la relación entre semi-ficciones e hipótesis es delicada y crucial. Las hipótesis son verificables por observación, para Vaihinger. Las ficciones, en cambio, son justificables, probando su utilidad para la vida. Mientras las hipótesis conducen al descubrimiento de cuáles son verdaderas, las ficciones son producto de la invención humana y tan solo pueden sostenerse provisionalmente.

Es de notar el hecho de que, otra vez, las ficciones son considerados constructos hipotéticos de los cuales fehacientemente se sabe que no son reales, no obstante resultan ser útiles, en particular en lo relativo al conocimiento. Según Vaihinger esto debería contribuir a atenuar la metafísica propia del realismo y a comprender que "la conclusión más falaz del hombre ha sido siempre el razonamiento de que porque algo es importante entonces debe ser cierto" (Vaihinger, 1924: 69). Su intención, en cambio, apuntaba a desvanecer lo que Fine denomina "el argumento explicativo del realismo", su pretensión de imponerse como una norma por default en la comprensión del estatuto de nuestras hipótesis (Fine, 1993: 9).

Por la vía contraria, el argumento de Vaihinger procede partiendo de la idea de que operamos con ficciones hasta que se demuestre lo contrario. Y esa demostrabilidad implica la eliminación parcial de la contradicción entre la hipótesis ficcional y lo que se tiene por real, así como también la eliminación de su auto-contradicción. Es decir, el tránsito epistemológico comienza por las ficciones y continúa por las semi-ficciones hasta arribar al plano hipotético de lo que puede ser probado.

En este trayecto los constructos hipotéticos, los como si, se emplean como andamios en torno a la constitución de un edificio de creencias e hipótesis verificadas, que luego son retirados cuando su propósito epistémico se ha cumplido. Las contradicciones y alteraciones que genera el vehículo fíccional no son "afecciones del raciocinio" que deben ser eliminados mediante un método como en Bentham, sino pasos formativos necesarios en el camino de comprender el mundo (Vaihinger, 1924: 26). Se alcanza un equilibrio en la creencia cuando llegamos a configurar algún sentido de realidad mediante nuestros útiles constructos ficcionales (Fine, 1993: 9). 
Para Vaihinger, como para su contemporáneo Dewey, no hay una armonía pre-establecida entre la racionalidad y la realidad. La racionalidad no es más que el ensamblaje parte a parte desde la experiencia en pos de chequear nuestra propensión a la inferencia y la construcción hipotética. En vez de intentar construir un método o un protocolo general para lidiar con las contradicciones o argamasar una teoría omni-abarcativa, lo que se propone es un procedimiento situado para ponderar graduadamente las contradicciones en nuestros sistemas de creencias, estableciendo un mecanismo de asimilación por andamios.

Sin embargo, al igual que en el caso de Bentham, la recuperación actual de la posición de Vaihinger no viene sin beneficio de inventario. En particular, nota Fine, depende de establecer un contraste dogmático entre descubrimiento (hipótesis) e invención (ficciones) y entre verificación y justificación utilitaria (Fine, 1993: 8). La ficcionalización es un procedimiento al uso que tiene un carácter transitorio: permite la forja de nuevos candidatos al valor de verdad y la reformulación de los contornos de lo que consideramos real. Se trata de una razón incremental sobre la base de un confiado naturalismo que Vaihinger comparte con pragmatistas como Dewey e instrumentalistas como Poincaré. "Al igual que el Wittgenstein tardío, Vaihinger piensa que nuestras formas ordinarias de pensamiento, que involucran una gran cantidad de actividades de tipo ficcional, son mayormente correctas" (Fine 1993: 10). Las construcciones hipotéticas nos ayudan a lidiar con las contradicciones aparentes por medio de un ejercicio práctico de asimilación y reformulación ficcional. Sin ficciones, nuestros sistemas de creencias serían racimos sin capacidad de crecimiento ni de tolerancia a las tensiones y contradicciones. Si nuestros sistemas estuvieran constituidos tan solo por ficciones, no se sostendrían como creencias en absoluto.

Quizás es por eso que el aspecto positivo, incremental, de andamiaje de los sistemas de creencias, se complementa subsidiariamente con una nota, un préstamo o herencia benthamita diríamos, que tracciona el entero procedimiento vaihingeriano. El tránsito desde la ficción a la hipótesis verificada establece una serie de dominios restrictivos para el ámbito de lo ficcional, en los cuales re-emerge con fuerza la idea de que se trata de procedimientos imaginativos que se efectúan sobre lo que conscientemente y de antemano se sabe que es o no es el caso. Como vimos antes, la primera condición de la ficcionalidad es su situación contradictoria respecto de lo que se tiene por real. En esta aproximación, como ocurría también en el caso de Bentham, se afirma el "notoriamente" de lo que es "notoriamente falso" o notoriamente otro respecto de lo existente, elidiendo la pregunta: ¿notorio para quién?

La anatomía vaihingeriana del fenómeno ficcional, no obstante, intentaba ser una caja de herramientas para probar la utilidad epistémica de las ficciones, para exhibir su carácter discreto, capilar, inescapable, como vía de acceso a un ámbito de conocimiento que, en el caso límite, transforma las ficciones contradictorias en hipótesis verificadas. Si bien se oponen como momentos de la labor incremental en la forja de la creencia, ficción y sentido de realidad dejan de oponerse en última instancia. Con ello, más bien, comienza a bosquejarse un esquema en el cual cualquier sentido de realidad que pueda obtenerse es el resultado de procedimientos que involucran, entre otros recursos, la operatoria ficcional.

Para Vaihinger las ficciones del como si son una forma de concebir un espacio legítimo para la construcción de modelos, la simulación, la elaboración de concepciones alternativas y empíricamente equivalentes de lidiar con los fenómenos (Fine, 1993: 11). Pese a los temores de los positivistas lógicos, no hay nada especialmente escéptico o idealista en esta perspectiva. Su carácter modélico y presentativo nos muestra al conjunto de nuestros sistemas de creencias como el resultado de una serie de procedimientos y prácticas, de haceres y hechuras. De esta manera no es extraño que en la presentación que hace Fine de Vaihinger, este autor sea considerado el precursor del paradigma del científico como modelizador que se ha difundido desde la posguerra (Fine 1993: 16). Vaihinger, de hecho, según Fine, debería ser reconocido como el heraldo o el filósofo de la modelización.

Y sin embargo todavía se extiende en el trasfondo conceptual que articula esta propuesta la necesidad, como en Bentham, de establecer distinciones entre lo que es tenido por real y lo que es presentado en forma de andamio incremental. Este rol de choque y tensión de las ficciones obtura quizás la oportunidad 
que residía en este modelo para reflexionar en torno al procedimiento por el cual continuamos distinguiendo entre el edificio y el andamio que se le añade provisoriamente.

El problema de las ficciones, en esta apreciación del legado de Vaihinger, no es tanto que sean andamios, sino que no son más que una etapa transitoria en el proceso del pensamiento y siguen estando en el linde exterior de lo que es tenido por real. Al igual que en las teorías parasitarias o derivativas de la metáfora, en las cuales la oposición se da entre metáfora y concepto, y cuando tenemos conceptos es porque la metáfora se ha cristalizado o necrosado, en esta teoría incremental de la ficción, la ficción necrosada o se desmonta o deviene parte del edificio de las hipótesis verificadas, por lo que es anulándose en tanto que ficción que accede finalmente a la dignidad de lo real.

En última instancia, si bien se trata de un avance respecto del modelo oposicional de Bentham, el de Vaihinger no es sino una forma de concebir la ficcionalidad como una prenda transitoria que se ofrece en sacrificio en la búsqueda de un concepto de realidad que continúa estipulándose de antemano.

\section{Frye y el espectro de lo plasmático como lo concebible}

El recorrido de este artículo se inició con unas consideraciones de Hayden White respecto de su concepto de la ficción como un constructo hipotético en sentido benthamita y vaihingeriano. Hemos analizado las ambivalencias y tensiones internas detrás de estas orientaciones respecto del concepto de ficción, que por lo demás se distinguen entre sí. El paso siguiente, y final, en este trayecto, consiste en recuperar la obra de un autor, el teórico literario Northrop Frye que, paradójicamente, fue muy importante en el planteamiento de Hayden White (White, 1992: 18), pero al que parece haber prestado poca atención, u obtenido escaso provecho de su compleja, sutil y fértil articulación de una perspectiva propia en torno al concepto de ficción.

La obra de Frye es difícil de resumir y presentar de manera sucinta. Considerado un espécimen inclasificable, a mitad de camino entre la herencia del formalismo en el medio angloamericano y las derivas del New Criticism, influido por los avatares de la teoría del mito, el existencialismo kierkegaardiano, las filosofías de la literatura y de la cultura de Erich Auerbach y Kenneth Burke, así como también por la herencia aristotélica, la poética de William Blake, la retórica renacentista, Longino, Vico y la hermenéutica teológica (Denham, 2015: 14), la obra de Frye articula una propuesta de rasgos únicos en el horizonte teórico del siglo XX (Cook, 1987; Denham, 2015; Hart, 1994; Lavagnino, 2014).

Esa propuesta encuentra su más rotunda configuración en su monumental Anatomía de la crítica (1957; Frye, 1977), texto canónico considerado el más influyente de la teoría literaria en el siglo XX en el ámbito anglosajón. Tanto allí como en Fables of Identity (1963) y Fearful Simmetry (1947) lo que se anuda es un modelo crítico que pretende constituirse como un paradigma para el análisis de los textos literarios como objetos culturales y de la experiencia literaria que se deriva de esos objetos. Ese modelo, posteriormente, se vio refinado, ampliado y aplicado en detalle en una larga secuencia de obras que, en el lapso de un tercio de siglo, hilvanó una de las más sutiles y complejas visiones del entramado literario y de su rol en la configuración y prefiguración de lo social. En lo que sigue expondré brevemente los rudimentos de ese modelo, ya que nos permitirá acceder a una tercera perspectiva, entiendo que más productiva y fértil, sobre el concepto de ficción.

Desde la Anatomía... hasta sus últimos textos mayores -notablemente los dedicados al estudio de las Escrituras, El Gran Código (Frye, 1988) y Poderosas palabras (Frye, 1996)- lo que encontramos es un modelo de análisis al que denominaré escénico-compositivo para analizar las diversas efectuaciones literarias. Pero ¿a qué se aplica ese modelo? A las presentaciones verbales que, en sus diversas formas, tienen lugar dentro de una determinada cultura en un momento dado (Frye, 1971: 17). Es un lugar habitual describir a Frye como un crítico mitológico y también se ha notado su empleo de un término sospechosamente platónico o jungiano, el de arquetipo. Sea, Frye es un teórico mythológico y arquetípico. ¿Pero qué quiere decir eso en este contexto? 
Un mito es, primariamente, una elaboración verbal que pretende dar cuenta del mundo. Por caso, en las sociedades tradicionales es a través del mito como se elaboran visiones de lo eminente, de lo digno de ser consignado y atesorado en el acervo de una cultura. De esta manera, y en estricto acuerdo con la teoría del mito en la que se enmarca Frye, y a distancia de la noción de sentido común sobre lo mitológico como lo fabuloso o lo opuesto a la razón o lo real, se trata de un orden de palabras que expresa un punto de vista autorizado sobre el mundo en el que se vive y se quiere vivir (Frye, 1971: 24).

Un señalamiento decisivo debe hacerse aquí: la unidad de análisis en este proyecto teórico no es nunca el enunciado o los términos que lo componen. El orden de palabras se enlaza mitológicamente en formas discursivas que, por definición, exceden la dimensión oracional. Este paso será crucial en lo que refiere al tratamiento del problema del concepto de ficción, y es uno que es imposible dar en un marco benthamita o vaihingeriano.

Como elaboraciones discursivas los mitos de creación del mundo, por ejemplo, tenían por función primaria proponer una interpretación y una elaboración hipotética de lo tenido por real por los hablantes. Un mito es, en suma, un instrumento de la producción mental (Frye, 1971: 19). Ese instrumento dispone signos como parte de un comportamiento verbal en el tiempo y en el espacio. Esa disposición aspira o pretende tener cierta coherencia. Para reconocer esa sistematicidad es que la teoría literaria debe darse un modelo de análisis, que es lo que Frye intenta desarrollar a lo largo de toda su obra.

El modelo de Frye para analizar el orden de palabras, en el paradigma presentado en la Anatomía... es de marcada ascendencia aristotélica. Tomando la héxada propuesta por el estagirita en la Poética como partes constitutivas de las presentaciones escénicas trágicas (mýthos, éthos, diánoia, melos, léxis y ópsis), Frye construye un proyecto crítico hermenéutico que encuentra en el mýthos una primera aproximación al orden de palabras como parte del comportamiento humano.

¿Cómo reconocer un orden en la disposición verbal? Pues diacrónicamente, en el tiempo, por medio de la captación de elementos constructivos, iteraciones, recurrencias, un ritmo, en suma, que en la secuenciación de sus elementos, típicamente descripciones de eventos y acciones, denominamos trama, o argumento o narración (Frye, 1963: 12). El mýthos de un relato implica el reconocimiento de un relieve y segmentación del despliegue narrativo en el tiempo.

Pero alternativamente podemos y solemos asir la disposición verbal por analogía no con los fenómenos rítmico-temporales, sino reconociendo recurrencias e iteraciones en el espacio, concentrándonos en los patrones de diseño que constituyen al objeto (Frye, 1971: 24). A esto Frye lo llama un arquetipo o un símbolo iterado. Los arquetipos de Frye no tienen relación alguna con sus homónimos jungianos, no implican ideas primordiales o patrones ejemplares platónicos, ni remiten a tipos ideales. Son typus, o figuras primarias, en el sentido de prototipos, modelos o principios constructivos básicos (arché como forma inicial de un typus; Frye 1963: 15). De esta manera la teoría de Frye se propone bajo la figura analógica de una filosofía del diseño verbal que encuentra en su analogía escultórica, arquitectónica o hasta musical, un modo de plantear el problema de la composición y el diseño aplicado a una materia sígnica.

Esto es relevante ya que para Frye, y apropiándose de una manera bastante personal del legado aristotélico, el significado de una obra literaria en un sentido sincrónico, el patrón total de sus símbolos o arquetipos, es su diánoia (Frye, 1977: 77), su tema o pensamiento.

Aquí emerge una figura central en el proyecto teórico de Frye: los elementos reconocidos no se oponen, sino que se articulan en un modelo tensivo, dialéctico, que no pretende resolver lo que distingue o discrimina en una única fórmula unitaria. Las palabras se disponen en una forma centrada en la figura de una tensión irresoluble. La indeterminación resultante es una figura crucial de este modelo.

Un mito como forma elemental de estructuración discursiva de un orden de palabras puede ser analizado como mýthos, en su ritmo diacrónico en el tiempo, o como diánoia en su patrón de diseño sincrónico y arquetípico en el espacio. Es así que encontramos un punto de ampliación crucial: contra lo que sugiere 
la caricatura que se le atribuye, el orden de palabras no se encuentra aislado como una mónada en un universo autotélico de significación (White, 2010: 264).

El mito, como mýthos-arquetipo (o diánoia) es un orden verbal que se despliega en un contexto actuado y performado socialmente. A este respecto, el mito es la contraparte verbal del rito, y el rito es la contraparte actuada del mito (Frye, 1963: 16). El universo del mito explora el ritmo, la recurrencia y la variación en el orden de palabras, y se despliega como un símbolo (esto es, en sentido estricto, como una contraparte no isomorfa; Harris, 2000: 23) del orden de la acción y el horizonte de lo social. La dimensión social de la crítica como exploración del mito implica considerar que no hay ningún principio de autonomía o autosuficiencia del orden de los signos (Frye, 1977: 461). El comportamiento verbal y el no verbal son continuos, y remiten ambos a un mismo universo de sentido. Cuando de Aristóteles a Ricoeur se afirma que el mýthos es una mímesis de la acción (mímesis práxeos) se está afirmando esto mismo, en la forma de una producción virtuosa, un acrecimiento de significado en el que el comportamiento verbal procede por simbolización y analogía, proveyendo contextos siempre ampliados para la significación de lo actuado, sea por medio de la palabra o no.

En este punto cobran importancia los ciclos analógicos y de identificación metafórica que emplean la potencia significante del mito y de los ritos para dotar de significado a lo que naturalmente no lo tiene. El mito es una unidad de significación que funciona, discursivamente, como la metáfora lo hace en el plano léxico. El mito individualiza, nomina, identifica. Así se establecen analogías y equivalencias lábiles, que se complementan por vía del ritual con las recurrencias percibidas en el entorno circundante: los ciclos diurnos, lunares, sexuales, anuales se constelan en un conjunto de experiencias y simbolizaciones compartidas. El mito es una de las primeras y más ubicuas formas de simbolización; fecunda y es fecundado a su vez por las formas de la interacción social (Frye, 1963: 18).

Hasta aquí lo que podría llamar la teoría ampliada del mýthos de Frye. Pero su proyecto crítico requiere el reconocimiento de dos dimensiones adicionales. En primer lugar, la idea de que los órdenes de palabras (una de cuyas primeras articulaciones culturalmente relevantes es el mito) están tensionados por una doble inscripción, una fuerza divergente: por un lado, tienden hacia sí mismos, centrípetamente, ya que el diseño verbal debe atender a los requerimientos constructivos en alguna medida. Lo que hacemos con las palabras y los signos depende, hasta cierto punto, de lo que puede hacerse materialmente con ellos, y de las formas culturalmente disponibles para emplearlos. Pero al mismo tiempo los órdenes de palabras componen objetos culturales que cumplen funciones prácticas (por vía de su inscripción ritual, cultural, etc.), y de esa manera no tienden hacia sí, sino centrífugamente hacia el mundo que simbolizan. Esta tensión centrífuga-centrípeta en la dirección de la simbolización tiene un nombre para Frye: desplazamiento (Frye, 1977: 182).

El desplazamiento es la tendencia, dentro del proceso de simbolización, a la centrifugalidad, convirtiendo a los objetos verbales diseñados de acuerdo con ciertos patrones constructivos, en formas representativas realistas o naturalistas que parecen meramente responder o adecuarse a requerimientos no verbales. La idea de un enunciado que simplemente describe o refiere eventos u objetos en forma realista, es el summum de la expresión verbal desplazada.

"En el mito vemos aislados los principios estructurales de la literatura; en el realismo vemos como los mismos principios estructurales (no otros parecidos) encajan dentro de un contexto de plausibilidad (...) El mito es un extremo del diseño literario; el naturalismo es el otro" (Frye, 1977: 182). De este modo, el mito es una pieza de diseño primaria y evidente, que lejos de esconder sus patrones, ritmos y principios constructivos, los resalta. Es puro género y convención. Pero cuanto más avanzamos en el tiempo encontramos formas genéricas que tienen por finalidad ocultar su carácter genérico. Hallamos una forma convencional que se niega como tal y se presenta a guisa de pura representación pasiva y adecuada de la realidad. Cuando eso ocurre, como es el caso del naturalismo y el realismo decimonónico o con el surgimiento del tipo de prosa descriptiva asociada a las estructuras verbales aseverativas empleadas en el discurso científico, nos encontramos ante lo que Frye llama la prosa desplazada. Prosa cuya función $y$ autoridad en una sociedad determinada puede ser muy eminente, pero cuyos recursos constructivos $y$ 
de diseño son exactamente los mismos que los empleados por las formas mitológicas supuestamente superadas.

De esta manera, en el proyecto crítico de Frye encontramos que éste dedica su segundo ensayo en la Anatomía... al estudio de las diversas formas en que las unidades mínimas de significación (símbolos o arquetipos) se vinculan con aquello que simbolizan o significan, en un espectro tensionado y gradual que va desde el poder performativo puro y no desplazado del kerygma (el condensado visionario que nomina el mundo y del que emergen luego los mitos) hasta los horizontes desplazados de las fases descriptivas y literales del signo, donde el símbolo se adecua a las convenciones del realismo en la forma de enunciados objetivos o a la manera de una pura notación abstracta (Frye, 1977: 114). El kerygma muestra la potencia de un lenguaje que crea el mundo. Las formas desplazadas, en cambio, se adaptan a él.

Entre un extremo y el otro se encuentra el entero conjunto de movimientos de ida y vuelta entre las tendencias al desplazamiento propias de las orientaciones realistas y las periódicas reversiones o articulaciones de formas verbales y discursivas que pretendiendo apartarse de las convenciones genéricas consideradas como naturalistas o realistas, simplemente adoptan otras convenciones y géneros.

El símbolo, como arquetipo o representación (en el sentido neutro de una presentación de un orden de signos que se vincula con lo que no tiene naturaleza sígnica; Harris, 2000: 77), queda prendado en el bascular espectral de estos desplazamientos. Lo cual revierte en una preciosa enseñanza respecto del realismo: hay una historicidad, una perspectiva diacrónica para la configuración realista, desplazada, que responde a la tensión centrípeto-centrífuga en el proceso de simbolización. Al igual que en Mímesis de Auerbach (Auerbach, 1968), para Frye se trata de mostrar las diversas maneras de concebir las formas de lo que llamamos realidad, de presentarla mediante escenificaciones y composiciones que toman como su material los elementos sígnicos, verbales y simbólicos disponibles en una determinada cultura.

Esta perspectiva incorpora una saludable plasticidad a nuestro sentido del diseño y composición de un orden de palabras que dota de significado a nuestro mundo. Lo que hoy denominamos mitos o mitologías son aquellas formas que, desde nuestro punto de vista, revelan de manera evidente sus elementos constructivos, cuando no sus vicios, sus patrones de diseño, sus recurrencias, sus secuencias rítmicas. Lo que ahora denominamos formas realistas son aquellas formas diseñadas y compuestas pero que leemos centrifugamente, como si simplemente respondieran a las presiones causales de un entorno no verbal.

La segunda y última dimensión que debemos incorporar para comprender el alcance de la teoría de Frye es su diseño multiplanar, en el que adopta de manera explícita una hermenéutica diatessarónica. ¿Qué significa esto en concreto? El diatessaron es, en términos teológicos, un texto orientado a establecer una armonía entre los cuatro Evangelios (White, 2010: 366), sobre la base de un reconocimiento de su solapamiento, contradicción parcial e irreductibilidad. En la teoría de la música es un intervalo de cuatro notas (a diferencia por ejemplo del diapasón, que es una diferencia de una octava) que produce una consonancia (absoluta en el sistema de la música pitagórica; Benson, 2003).

Aplicado a soportes verbales, y en particular en la doctrina hermenéutica sacra el diatessaron queda magníficamente expresado en la fórmula de Agustín de Dacia "Littera gesta docet, quid credas allegoria, moralis quid agas, quo tendas anagogia" ", la cual se aplicó a la lectura de los evangelios y posteriormente cobró nueva vida en la hermenéutica renacentista, a partir del reconocimiento de los tradicionales cuatro niveles de la interpretación: el literal, el alegórico, el moral o tropológico y el anagógico. En esta hermenéutica estos niveles consonan armónicamente, son irreductibles entre sí (como cada nota en un acorde) y se requieren recíprocamente.

La hermenéutica diatessarónica de Frye se plasma, desde su Anatomía... en adelante en la forma de un diseño de consonancia en torno a cuatro niveles, cada uno de los cuales a su vez se reparte en tétradas

\footnotetext{
1 "La letra enseña los hechos, la alegoría lo que has de creer, el sentido moral lo que has de hacer y la anagogía a dónde has de tender".
} 
irreductibles. Dedica a cada nivel un ensayo en su Anatomía...: el primer ensayo está dedicado a los modos de la agencia, lo que los personajes pueden o no pueden hacer y los tipos de intervención narrativa concebibles (en un espectro graduado que va desde los dioses omnipotentes hasta las figuras de sumisión inmitigada del teatro del absurdo). El segundo ensayo escruta los modos de los símbolos, acorde a la teoría del desplazamiento ya consignada. El tercero despliega su celebrada teoría del mýthos, recuperada por ejemplo por Hayden White en Metahistoria (White, 1992: 18-21), en la cual profundiza en las modalidades y gamas de posibilidades mediante las cuales se elabora el significado a través de mýthos y arquetipos en las convenciones recurrentes de la comedia, el romance, la tragedia y la sátira. El cuarto ensayo elucida cuáles son los radicales de presentación, las situaciones retóricas típicas mediante las cuales se realizan materialmente las tramas, agencias y símbolos: el epos, la lírica, el drama y la ficción en prosa.

El paradigma crítico de Frye, entonces, se ofrece como una delicada caja de herramientas en la que agencias, símbolos, mýthos y situaciones retóricas consonan y reverberan recíprocamente entre sí, como dimensiones irreductibles del orden de las palabras. La labor crítica consiste en estudiar la forma en que diatessarónicamente consonan las composiciones verbales.

Lo que Frye afirma confiadamente, desde la Anatomía... en adelante, es que tenemos un modelo de análisis disponible para observar cómo se ha diseñado, compuesto, montado y escenificado el orden de palabras en cada contexto práctico. De esta manera lo que ofrece es "una concepción de la literatura como cuerpo de creaciones hipotéticas que no están necesariamente comprometidas en los mundos de la verdad y de los hechos, ni necesariamente apartadas de ellos, sino que pueden entablar cualquier clase de relación con ellos, yendo de la más explícita a la menos" (Frye, 1977: 127).

El punto de la ficción, en Frye, justamente es el de ser una estructura verbal hipotética (Frye 1977: 99), un constructo hipotético como en Bentham o Vaihinger ciertamente, pero que tiene propiedades específicas. Lo que hacen las ficciones es permitir "la presentación de las cosas tal como podrían haber ocurrido", lo que los griegos llamaban lo plasmático. "Para el crítico literario todo lo que se diga con palabras es plasmático, y la verdad y la falsedad representan las direcciones o tendencias que siguen o que se piensa que van a seguir las estructuras verbales" (Frye, 1980: 28). La misma estructura verbal o secuencia léxica, puede ser un mito eminente de creación del mundo o una fábula desacreditada. La igualdad gramatical se complementa con una diferencia en autoridad social, en la forma de un reconocimiento o reacción ante la experiencia literaria. En este sentido ningún análisis inmanente puede bastarnos para comprender la relación entre la semiosis ficcional y su significación social.

La abigarrada configuración de elementos y planos de análisis en Frye constituye un paradigma para la construcción de una matriz analítica destinada a recorrer esas estructuras verbales hipotéticas que conjuntamente denotan el vasto espacio de lo concebible e imaginable mediante órdenes y secuencias de palabras. La ficción, como lo plasmático, es el vasto espectro de modos de concebir agencias, símbolos, mýthos y situaciones retóricas. Estos modos tienen una finalidad: dar cuenta y a la vez incidir en la experiencia, modelarla, prefigurar los modos posibles de la práxis. Si el mito es la contraparte verbalizada del rito y éste la contraparte actuada del mito, en conjunto ambos se interrogan acerca de de qué es lo que puede concebirse, qué es lo que puede hacerse, quién puede hacerlo y cuáles son las formas mediante las que procede el lazo social.

Para Frye es mediante las estructuras verbales hipotéticas que se postulan los variados espectros de agencias, símbolos, géneros y mýthos, los cuales convergen en un sistema escénico-compositivo, un modelo de diseño verbal que tiene por objeto postular, disponer, concebir y al mismo tiempo tensionar, disputar y problematizar nuestro concepto de realidad.

Es entonces en esta tercera teoría sobre la ficción que conseguimos finalmente articular una perspectiva que trasciende la oposición entre ficción y realidad. Esa perspectiva nos muestra el carácter espectral y graduado, dialéctico, tensivo, disputado de los horizontes de lo concebible que se escenifican y componen mediante dispositivos ficcionales. Y es dentro de esos horizontes que se afirma un subconjunto de prácticas hegemónicas que, contextual, situada, precariamente, se presenta con el 
marbete de lo inexorable. En Frye, finalmente, la ficción no se opone a lo real. Antes bien, lo real es el subconjunto que plasma una inexorabilidad precaria, pero socialmente relevante, en el espectro siempre bullente y disputado de lo concebible.

\section{Descerrajando grilletes a modo de conclusión}

White, como lo muestra la cita que da inicio a este artículo, buscaba una manera de rehabilitar una discusión compleja y sutil en torno a los vínculos entre discurso y conocimiento historiográfico, literatura y ficción. Su apelación al legado benthamita y vaihingeriano intentaba mostrar la limitación de la tradicional asociación entre ficción, fingimiento, simulación, mentira y falsificación. Al resaltar el componente ficcional del discurso historiográfico deseaba mostrar su carácter diseñado, compuesto, prefigurado, apelando para ello a las técnicas de análisis disponibles en la teoría literaria y la teoría de la ficción. De allí su recuperación de la figura del constructo hipotético y su filiación dentro del linaje que se remonta a Vaihinger y Bentham.

El resultado de este recorrido apunta a mostrar algo bastante simple: esa apelación no es suficiente, porque ni Bentham ni Vaihinger consiguen dar el paso requerido para liberar a la ficción del cautiverio filosófico en el que ha permanecido. Cautiverio que, en el período extenso que va de Platón y la degradación ontológica, pasando por Bentham y la fetidez ponzoñosa hasta alcanzar la simulación ilocucionaria de Searle y el hacer-creer de Currie, apenas comienza a morigerarse gracias al andamio incremental vaihingeriano. La conclusión a la que arribo es que es recién dentro del horizonte abierto por la filosofía del diseño verbal de Frye que algo así como una teoría positiva de la ficción puede comenzar a enunciarse.

En este horizonte, y como espectro plasmático de lo concebible, la ficción no es lo que se opone a lo real. Más bien es lo que nos permite tener un concepto de realidad.

En el devenir de los desplazamientos la ficción no es ni la ponzoña fétida oposicional benthamita que puede eliminarse mediante paráfrasis, ni el andamio incremental vaihingeriano que en su logro constructivo se aniquila a tenor de un sentido de realidad consolidado. Para Frye la realidad es el subconjunto desplazado dentro de la vasta gama concebible de estructuras verbales hipotéticas. Como subconjunto ficcional decantado, lo real no es más que la ficción desplazada hasta uno de sus límites, aquel en que lo concebible cede imaginativamente ante el embrujo de lo inexorable

Las ficciones pueblan nuestro mundo. Para Frye son uno de los más ubicuos instrumentos de la creación mental. De manera más específica, en su modalidad narrativa constituye una de las tecnologías de la palabra más potentes para concebir las formas de la agencia humana y prefigurar el horizonte de lo social (Frye, 1971: 86). Así lo que puede encontrarse en Frye es un poderoso argumento para unir el horizonte de la ficción al contexto de la práxis, resaltando las relaciones entre fictio y factum, de manera que no sea el modelo de la duplicidad, la simulación y la degradación ontológica lo que se aúne a la consideración del vehículo fíccional, sino su carácter disposicional, de diseño e ideación.

La remisión es menos a fingere que a recuperar el sentido de modelado, escenificación, composición (contrive, concoct). En este punto la filosofía de la literatura de Frye es tanto una teoría del simbolismo, como una visión sinóptica de la cultura en pos de elaborar una teoria escénico-compositiva de la expresión verbal. En el camino de forjar tal teoría, se afirma aquí, Frye arriba a un concepto de ficción que rompe con la concepción oposicional, derivativa o meramente de andamiaje del concepto de ficción, para articular una concepción positiva y productiva de la misma, que explora las tensiones y consonancias irreductibles que se extienden ante el vasto espectro de lo que podemos concebir. 


\section{Referencias}

Auerbach, E. (1968). Mimesis: The Representation of Reality in Western Literature. Princeton University Press.

Benson, D. (2003). A Smoother Pebble: Mathemathical Explorations. Oxford University Press.

Bentham, J. (1932). The Theory of Fictions. Kegan Paul. Londres.

Bentham, J. (1970). Of Laws General. The Athlone Press. Londres.

Bentham, J. (1973). Fragmento sobre el Gobierno. Aguilar. Madrid.

Bentham, J. (1981). Tratados de Legislación Civil y Penal. Editorial Nacional. Madrid.

Bentham, J. (1983). Deontology. Clarendon Press. Oxford.

Blumenberg, H. (1999). Las realidades en que vivimos. Paidós. Barcelona.

Cook, D. (1987). Northrop Frye. A Vision of the New World. St.Martin's Press. Nueva York.

Currie, G. (1990). The Nature of Fiction. Cambridge University Press.

Denham, R. (2015). Northrop Frye and Others. University of Ottawa Press.

Fine, A. (1993). “Fictionalism”, En Midwest Studies in Philosophy. XVIII. 118.

Frye, N. (1963). Fables of Identity. Harcourt Brace Jovanovich. Londres.

Frye, N. (1971). The Stubborn Structure. Methuen. Londres.

Frye, N. (1977). Anatomía de la crítica. Monteávila. Caracas.

Frye, N. (1980). La escritura profana. Monteávila. Caracas.

Frye, N. (1988). El gran código. Monteávila. Caracas.

Frye, N. (1996). Poderosas palabras. Muchnik. Barcelona.

Harris, R. (2000). Rethinking Writing. Continuum. Londres.

Harrison, R. (1983). Bentham. Kegan Paul. Londres.

Hart, J. (1994). Northrop Frye. The Theoretical Imagination. Routledge. Londres.

Hart, H.L.A. (1982). Essays on Bentham. Jurisprudence and Political Theory. Clarendon Press.

Helfer, M. (1996) The retreat of representation: the concept of darstellung in German critical discourse. State University of New York Press. Albany.

Herman D., Jahn M. y Ryan M.L. (eds) (2005). Routledge Encyclopedia of Narrative Theory. Routledge. Nueva York.

Lavagnino, N. (2013). "Cinco tesis en torno a las arquitexturas del lenguaje histórico". En Signos Filosóficos UAM. Vol XV. XXX. México. 119149.

Lavagnino, N. (2014). "Specters of Frye”. En Storia della Storiografia. Vol.65. I. Roma. Italia. 131143. 
Schlick, M. (1932). "Positivism and Realism”. En Logical Positivism. Kluwer. Nueva York.

Searle, J. (1979). "The Logical Status of Fictional Discourse”. En Expression and Meaning: Studies in the Theory of Speech Acts. Cambridge University Press.

Vaihinger, H. (1924). The Philosophy of “As If”. Kegan Paul. Londres.

White, H. (1992). Metahistoria. La imaginación histórica en la Europa del siglo XIX. Fondo de Cultura Económica. México.

White, H. (2003). El texto histórico como artefacto literario. Paidós. Barcelona.

White, H. (2010): The Fiction of narrative. Johns Hopkins University Press, Baltimore. 